\title{
Do Decision-Making Styles Help Explain Health-Risk Behavior among University Students in Addition to Personality Factors?
}

\author{
Jozef Bavolár, Mária Bačíkova-Slešková \\ Pavol Jozef Šafárik University in Košice, Slovak Republic
}

\begin{abstract}
Previous research has indicated that certain decision-making styles are associated with decision outcomes. This article focuses specifically on one area of decision outcomes - health-risk behavior - and examines if decision-making styles explain the variance in risk behavior over the Big Five factors. Five decision-making styles (rational, intuitive, dependent, avoidant, and spontaneous) and five types of risk behavior (alcohol use, internet use, junk food consumption, cigarette smoking, condom use) were identified in 374 university students. The results differ among the types of risk behavior, although generally, decision-making styles help to improve the models explaining risk behavior in the case of alcohol use and problematic internet use with the avoidant and dependent styles having the most prominent role.
\end{abstract}

Key words: decision-making styles, health-risk behavior, alcohol use, cigarette smoking, internet use

\section{Introduction}

The health-risk behavior of university students has been extensively studied (e.g., Keller et al., 2008; Steptoe et al., 2002), as it can have serious consequences on later life. Several health-risk behaviors have been identified in research such as substance use, risk sexual behavior, risk driving, sedentary behavior, prob-

\footnotetext{
Acknowledgment

This study was supported by the Slovak Research and Development Agency under the contracts no. APVV-0253-11 and APVV-15-0662 and the Grant Agency of the Ministry of Science, Research and Sport of the Slovak Republic and the Slovak Academy of Sciences VEGA 1/0713/15.
}

Correspondence concerning this article should be addressed to Jozef Bavolar, Department of Psychology, Faculty of Arts, Pavol Jozef Šafárik University in Košice, Moyzesova 9, 04001 Košice, Slovak Republic. E-mail: jozef.bavolar@upjs.sk

Received May 4, 2017 lematic internet use and unhealthy eating habits. In the present study we focus on those that belong to the most prevalent among university students. There is strong evidence that the incidence of three types of risk behavior (alcohol use, smoking, risk sexual behavior) tend to cooccur among young adults (Meader et al., 2016). Further, keeping good eating habits after starting university is challenging (Deshpande, Basil, \& Basil, 2009) and junk food consumption is highly prevalent in this population (Racette et al., 2005). Similarly, the increase of internet availability is related to the increase in problematic internet use, especially in adolescence and emerging adulthood (Anderson, Steen, \& Stavropoulos, 2017).

Previous research has identified many risk and protective factors of risk behavior, including demographic, social and personality characteristics. Although the relationships of personality factors including the Big Five factors with health-risk behavior have been well-mapped (e.g., Hong \& Paunonen, 2009), the role of cognitive characteristics such as information pro- 
cessing modes has rarely been studied (e.g., Jones, Ross, \& Hartmann, 1992). Decision-making styles, as a specific way of information processing in a decision context (Kozhevnikov, 2007), are related to a variety of decision outcomes (Bruine de Bruin, Parker, \& Fischhoff, 2007), even when studied together with the Big Five personality factors (Dewberry, Juanchich, \& Narendran, 2013; Wood \& Highhouse, 2014). However, their role in risky behavior has not been investigated directly before. While previous studies focused on the role of decisionmaking styles in general indicators of decision quality operationalized as a composite score of heterogeneous decision outcomes, the focus on specific situations can provide a more detailed picture reflecting the characteristics of different decision contexts. This article aims to investigate the role of decision-making styles in health-risk behavior, and more specifically, if decision-making styles can explain the variance in health-risk behavior over and above the Big Five factors.

\section{Decision-Making Styles and Risk Behavior}

Decision-making styles are the ways people make decisions and they are considered to be stable characteristics manifested in a variety of decision-making situations. Researchers differ only slightly in the definitions of decision-making styles and higher heterogeneity is visible in their classification. Scott and Bruce (1995, p. 820) have defined decision-making styles as "the learned habitual response pattern exhibited by an individual when confronted with a decision situation. It is not a personality trait, but a habit-based propensity to react in a certain way in a specific decision context". Kozhevnikov (2007) views decision-making styles as a sub-component of cognitive styles and Appelt et al. (2011), in a review of decisionmaking measures, state that the instruments originally constructed to measure cognitive styles are often used to measure decision-making styles. The current study has adopted the classification model proposed by Scott and Bruce (1995) who have identified five decisionmaking styles (rational, intuitive, dependent, avoidant, spontaneous) in four separate populations and have described them in behavioral terms. The rational style is characterized by the search for and logical evaluation of alternatives. The intuitive style is characterized by attention to detail and a tendency to rely on feelings while the dependent one is characterized by the search for and reliance on the advice of others. The avoidant style is the tendency to avoid decisions whenever possible and the spontaneous style is characterized by a sense of immediacy and desire to complete the decision-making process as soon as possible. The styles are interrelated and a person can use more of them or switch between them in various decision situations.

The question of correlates of decision-making styles in the real world is essential in relation to the current research. The association of all decision-making styles postulated by Scott and Bruce (1995), except for the intuitive style, have been reported in relation to life outcomes (Galotti et al., 2006). Parker, Bruine de Bruin and Fischhoff (2007) found the four decision-making styles, with the exception of the dependent style, to be related (rational and intuitive positively, avoidant and spontaneous negatively) to decision outcomes operationalized as a broad area of life situations including risk behavior. In two studies similar to the current one, decisionmaking styles and personality factors together have accounted for a substantial amount of variance in general indicators of decision outcomes (Dewberry, Juanchich, \& Narendran, 2013; Wood \& Highhouse, 2014). These studies also report associations between decisionmaking styles and the Big Five factors, where the rational, intuitive and dependent styles are positively related to extraversion, openness, 
agreeableness, conscientiousness and emotional stability, while the pattern is the opposite when the avoidant and spontaneous styles are considered.

When inspecting the question of real-life correlates of decision-making styles in more detail, the research concerning the associations between decision-making and health-risk behavior has mainly focused on the consequences of substance use on decision-making abilities (e.g., Clark et al., 2006; Zorlu et al., 2013). Phillips and Ogeil (2011) have found that a greater risk of alcohol related problems was linked to lower vigilance scores and increased tendencies towards procrastination. A higher risk of gambling problems was associated with lower decisional self-esteem and increased proneness to hypervigilance or panic. The authors summarize that problem drinkers are avoidant and problem gamblers are impulsive. Moreover, stimulant users report less competent and more maladaptive decision-making styles compared with controls (Gorodetzky et al., 2011). While no differences were found in the two styles viewed as non-adaptive (buck-passing and hypervigilance), the control group reported more frequent use of the only competent decision making style - vigilance - in comparison with cocaine users and less frequent use of procrastination in comparison with amphetamine users (Gorodetzky et al., 2011).

The avoidant decision-making style is similar to the group of avoidance coping strategies that has been found to be related to alcohol use (Cooper et al., 1992; Feil \& Hasking, 2008) and internet addiction (Al-Gamal, Alzayyat, \& Ahmad, 2015). Similarly, the dependent style is close to social support seeking although it was not a significant predictor of alcohol use (Çavusoglu, 2010; Sacco, Bucholz, \& Harrington, 2014). The influence of social support is probably more important in ceasing rather than in retaining risk behavior (e.g., Westmaas, Bontemps-Jones, \& Bauer, 2010).
The spontaneous decision-making style has characteristics close to the description of impulsiveness. Impulsive decision-makers have a higher probability of risky sex, use of alcohol or marihuana more often before sex and are more likely to engage in intercourse in comparison with the rational decision-makers (Donohew et al., 2000). Similarly, Tuinstra (1998) found that impulsive adolescents exhibit more unhealthy behavior (alcohol, smoking, soft drugs), while the other three studied decision-making styles (docile, panic and self-confidence) were not related to the risk behavior.

\section{Big Five Factors and Risk Behavior}

The concept of five general factors (the Big Five) is generally accepted as a basic theoretical concept of personality structure and the role of the five factors belonging to this model (extraversion, agreeableness, conscientiousness, openness to experience, and neuroticism; Costa \& McCrae, 1992) in risk behavior has been widely studied. Alcohol consumption has been operationalized in studies differently (binge drinking, number of drinks per occasion) with heterogeneous associations with the Big Five traits. While alcohol consumption among young adults can be predicted through a high level of neuroticism associated with a low level of agreeableness (Coëffec, 2011), women with higher levels of openness to experience were more at risk for heavy and problematic alcohol use (Martin et al., 2015). Moreover, higher levels of openness to experience and neuroticism were significantly associated with an increased risk of using cigarettes during one's lifetime (Zvolensky et al., 2015) and openness to experience was the sole personality variable accounting for the differences in smoking prevalence (McCann, 2010). Friedman (2000) views the relationship between neuroticism and health-risk behavior as more complicated and distinguishes two types of neurotic personalities. Firstly, 
those characterized by emotional instability and pessimism, which can lead to unhealthy behavior and secondly, those who are more anxious and have lower well-being but engage less in risk behavior. When Hong and Paunonen (2009) combined three risk-taking behaviors (tobacco consumption, alcohol consumption, speeding in an automobile), low conscientiousness and low agreeableness were uniformly associated with this cluster of potentially health damaging behaviors. Extraversion was additionally associated with alcohol use.

\section{Present Research}

As decision-making styles are significant predictors of decision outcomes, the main aim of the current study was to investigate their role in a more specific outcome - health-risk behavior (aim 1). Moreover, as the Big Five factors are widely recognized factors of risk behavior, we were also concerned with the role of decisionmaking styles in selected types of risk behavior in addition to them (aim 2). The model of five decision-making styles by Scott and Bruce (1995) belongs to the most widely adopted and the role of their five styles in five types of risk behavior among university students - alcohol use, cigarette smoking, problematic internet use, risk sexual behavior and junk food consumption - was tested. As noted earlier, decisionmaking styles solely or together with the Big Five factors belong to predictors of decision outcomes (Dewberry, Juanchich, \& Narendran, 2013; Wood \& Highhouse, 2014), but these outcomes were operationalized very broadly as a summation of a range of heterogeneous situations with no attempt to study their subgroups. Two of the previous studies (Bruine de Bruin, Parker, \& Fischhoff, 2007; Dewberry, Juanchich, $\&$ Narendran, 2013) used the Decision Outcomes Inventory containing health-related items (e.g., diagnosis of sexually transmitted diseases, unplanned pregnancy, vomiting after alcohol use, driving while drunk, type 2 diabetes diagnosis) so it can be hypothesized that decision-making styles play a significant role even when focusing on this narrower group of decision outcomes. As decision-making styles are related to some Big Five factors but can be considered as more specific constructs, it was expected that decision-making styles could explain an additional variability in risk behavior that cannot be explained by the Big Five factors only.

\section{Methods}

\section{Participants and Procedure}

The first part of data was collected from university students in Eastern Slovakia in the second round of the longitudinal SLiCE (Student Life Cohort in Europe) study (www.slicestudy.eu), as decision-making styles were not measured in its first round. From the 4062 students asked by the message at their university information system, 600 provided data by completing an online questionnaire in the first round (response rate $=14.8 \%$ ) and 237 participated also in the second round. The complete data for all measures used in the present study were obtained from 207 students (age 19-36, $M_{\text {age }}=$ $21.4, S D_{\text {age }}=1.53,83.6 \%$ females). The participants present only in the first round differed from those continuing also in the second round in alcohol use $(F(1,588)=9.67, p<.05)$, smoking $\left(\chi^{2}(1)=9.48, p<.01\right)$ and extraversion $(F(1,588)=3.96, p<.05$; in all cases, a higher score in the first group). As the initial sample was disproportionately dominated by women, we also distributed the questionnaires to faculties providing technical education in order to counterbalance the gender ratio. 170 students completed the measures during the classes and the responses from 167 students (only males were present at the classes) with at least one risk-behavior indicator were used (age 19-26, 
$\left.M_{\text {age }}=22.6, S D_{\text {age }}=1.38\right)$. The mean age of whole sample $(N=374)$ was $21.92(S D=1.58)$ with $45.9 \%$ females.

\section{Measures}

Decision-making styles were assessed by the General Decision-making Styles questionnaire (GDMS, Scott \& Bruce, 1995) with five subscales examining the five decision-making styles - rational (e.g., My decision-making requires careful thought), intuitive (e.g., When making decisions I rely upon my instincts), dependent (e.g., I use the advice of other people in making my important decisions), avoidant (I postpone decision-making whenever possible) and spontaneous (e.g., I often make impulsive decisions). The measure contains 25 questions - five in each subscale and all measured on a scale from strongly disagree (1) to strongly agree (5). Higher scores in each subscale as the sum of the related items mean that this style is used more frequently. The Slovak version was translated from English by a native English speaking translator and back-translated. It showed good psychometric characteristics and similar factor structure as foreign versions (Bavol'ár \& Orosová, 2015).

The Big-Five personality traits were identified by the short Ten Items Personality Inventory (Gosling, Rentfrow, \& Swann, 2003) using two items for each factor - openness to experience, conscientiousness, extraversion, agreeableness and emotional stability. The scores in this scale are similar to those obtained by longer Big Five measures (Renau et al., 2013). The factors had Cronbach's alphas in lower levels, but still acceptable for two-item subscales (Schmitt, 1996).

Alcohol use was assessed by The Alcohol Use Disorders Identification Test (AUDIT, Bohn, Babor, \& Kranzler, 1995). Ten questions are divided into three subscales - consumption, dependence and alcohol-related problems although only the total score was used in the present study. As the score in items ranges from 0 to 4 , the total score varies from 0 to 40 with values higher than 7 as indicators of hazardous and harmful alcohol use.

The Generalized Problematic Internet Use Scale 2 (GPIUS2, Caplan, 2010) was used to assess problems with the use of the internet. The measure consists of 15 items and the total score as a sum of them was computed with higher values standing for more severe problems with internet use.

The next that examined a type of risk behavior was junk food consumption. The score was computed as the sum of four items inspecting the frequency of consumption of four unhealthy kinds of food [sweets (chocolate, candies), cakes/cookies, snacks and fast food]. The answers were coded from several times a day (1) to never (5) and recoded to have higher scores as a higher level of risk behavior.

One of the questions identifying smoking was selected for the analysis - if participants had smoked at least one cigarette during the last 30 days (yes/no). Risky sexual behavior was operationalized as the use of a condom during the first sexual intercourse (yes/no - 35 of 233 students (15\%) with sexual experience did not use one).

\section{Statistical Analysis}

Firstly, correlations among the decision-making styles, Big-Five personality traits and risk behavior were examined using Pearson, Kendall's tau and point-bisserial correlation. A Log transformation was conducted on the results of AUDIT, GPIUS2 and junk food consumption to meet the assumptions of normality and homoscedasticity needed for the following linear regression models. In order to obtain standardized regression coefficients, these dependent variables were standardized using $z$ scores and risk behavior indicators were transformed 
using $\ln$ (variable +2 according to the minimum score in standardized scores) for alcohol use, internet use and junk food consumption. In order to assess the role of decision-making styles in health-risk behavior, they were examined as predictors in linear and binary logistic regression models according to the type of dependent variable (linear regression for alcohol use, internet use and junk food consumption, logistic regression for smoking and condom use). Next, the incremental prediction of decisionmaking styles was examined when the Big-Five personality traits were inserted into the first step and decision-making styles into the second step of regression. As gender differences in healthrisk behavior have previously been acknowledged (e.g., Steptoe et al., 2002), gender was also included in all models to control its effect. All risk behavior indicators were coded with the higher values meaning a higher level of risk behavior. All data analyses were conducted in SPSS 21.

\section{Results}

The relationships (Table 1) between the decision-making styles and personality factors are in most cases significant but mostly weak with the exception of conscientiousness. It is positively related to the rational and intuitive styles and negatively to the avoidant and spontaneous styles. The intuitive style is positively and avoidant style negatively related to four out of the five personality factors. The overall tendency in relationships between decision-making styles and risk behavior is that the first three decision-making styles (the rational, intuitive, and dependent) tend to be related to risk behavior negatively, while the other two styles (avoidant and spontaneous) positively. However, the correlations are predominantly weak and not significant. As the associations among risk behaviors are very weak with one exception (alcohol use and smoking), an omnibus in- dicator of risk behavior could not be used and role of decision-making styles and the Big Five factors was examined separately for each type of risk behavior.

\section{Decision-Making Styles and Risk Behavior}

A multiple regression analysis (linear regression for alcohol use, problematic internet use and junk food consumption, binary logistic regression for cigarette smoking and condom use) found that decision-making styles together with gender explained 6 to 13 percent of variance in all kinds of risk behavior and the models were significant in alcohol use and internet use. Table 2 shows that the position of decision-making styles in risk behavior varied in the models, where the avoidant style was positively related to alcohol use and internet use and the intuitive style negatively to internet use and junk food consumption. The dependent style was associated positively with problematic internet use and negatively with alcohol use, while the spontaneous style was related to the higher probability of smoking.

\section{Incremental Prediction of Risk Behavior over the Big Five}

The role of decision-making styles as predictors of the studied types of risk behavior over and above personality factors was examined in hierarchical regression models with the Big Five factors entered firstly and followed by the decision-making styles inserted in the second step. As shown in Table 3, the Big Five factors significantly predicted four types of risk behavior and decision-making styles brought incremental prediction in alcohol use and problematic internet use. When examining the particular styles, the intuitive style predicted problematic internet use (negatively), the avoidant style alcohol use (positively) and the rational style condom use (negatively). The dependent style 


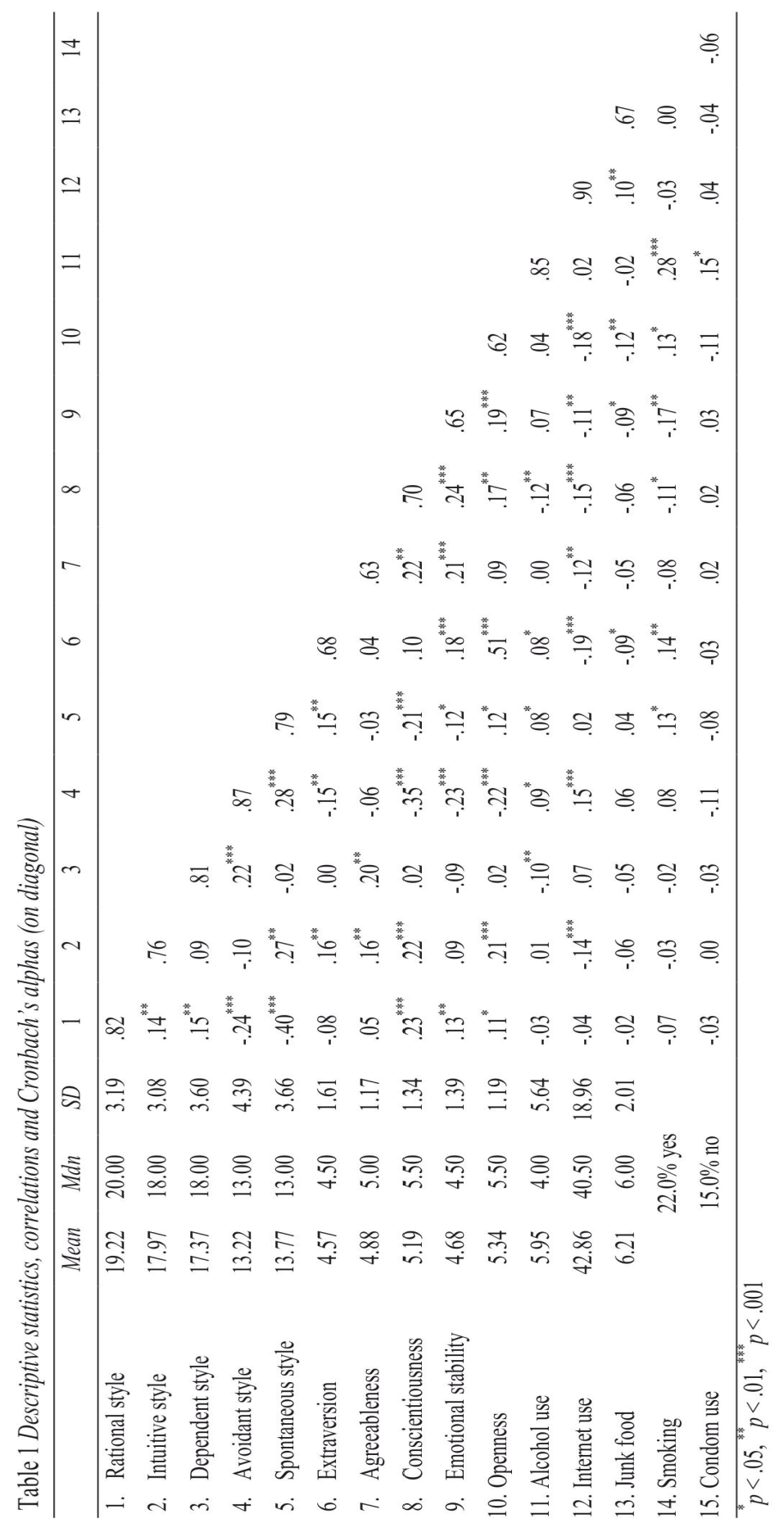


Table 2 Regression models inspecting role of decision-making styles in health-risk behavior

\begin{tabular}{|c|c|c|c|c|c|}
\hline & $\begin{array}{c}\text { Alcohol use } \\
\beta\end{array}$ & $\begin{array}{c}\text { Internet use } \\
\beta\end{array}$ & $\begin{array}{c}\text { Junk food } \\
\beta \\
\end{array}$ & $\begin{array}{l}\text { Smoking } \\
\text { OR }\end{array}$ & $\begin{array}{c}\text { Condom use } \\
\text { OR }\end{array}$ \\
\hline Gender $(\mathrm{M}=1)$ & $.30^{* * *}$ & $.21^{* *}$ & -.05 & .69 & 2.04 \\
\hline Rational style & -.02 & -.01 & .01 & 1.02 & .87 \\
\hline Intuitive style & .02 & $-.10^{* * *}$ & $-.06^{*}$ & .94 & 1.04 \\
\hline Dependent style & -.04 & $.07^{*}$ & -.05 & .98 & 1.04 \\
\hline Avoidant style & $.07^{* *}$ & $.09^{* *}$ & .02 & 1.02 & .92 \\
\hline Spontaneous style & .05 & .02 & .03 & $1.10^{*}$ & .93 \\
\hline $\begin{array}{l}\mathrm{R}^{2} \text { (Nagelkerke for } \\
\text { smoking and condom use) }\end{array}$ & .13 & .11 & .03 & .04 & .06 \\
\hline $\begin{array}{l}F\left(\chi^{2} \text { for smoking and }\right. \\
\text { condom use })\end{array}$ & $9.34^{* * *}$ & $7.71^{* * *}$ & 1.90 & 10.72 & 8.47 \\
\hline
\end{tabular}

Note. $\beta$ - standardized regression weight, $\mathrm{OR}$ - odds ratio ${ }^{*} p<.05,{ }^{* *} p<.01, \stackrel{* * *}{p}<.001$

predicted internet use positively, but alcohol use negatively. When compared with the previous models, which did not include the Big Five factors, differences were found in five cases across all of the examined types of health-risk behavior with three styles no longer significant and two styles becoming significant.

\section{Discussion}

The role of decision-making styles in various kinds of risk behavior was the center of interest in this study. Risk behavior included alcohol use, problematic internet use, junk food consumption, cigarette smoking, and risk sexual behavior. Multiple linear or binary logistic regression models were used to assess the role of the decision-making styles when inserted alone or after the Big Five factors. Previous studies have reported the role of decision-making styles in different decision outcomes (Bavolár \& Orosová, 2015; Galotti et al., 2006), and partially also when considered together with the Big Five factors (Dewberry, Juanchich, \& Narendran, 2013; Wood \& Highhouse, 2014). The current study confirmed these findings in the selected context but only partially - separately as well as when added after the Big Five factors, decision-making styles were able to explain a substantially higher proportions of variance in two kinds of risk behavior - alcohol use and problematic internet use. This result can be compared with the study most similar to ours (Wood \& Highhouse, 2014) where the decision-making styles showed incremental predictive validity when added to the Big Five factors predicting decision quality rated by participants themselves, but not when rated by their peers. It points to the possibility that the subjective rating of one's own decisions can be influenced by the stable view of the participant's personality manifested in the decision-making styles as well as in decision outcomes evaluation. In contrast, the more objective data such as peer evaluation or even assessment of one's own risk behavior are subject to subjective adjustment to a much lesser degree (compare Pitel \& Mentel, 2017). This explanation can be supported even by the fact that not only decision-making styles, but also the Big Five factors were weaker predictors of the evaluation of decision quality from peers 


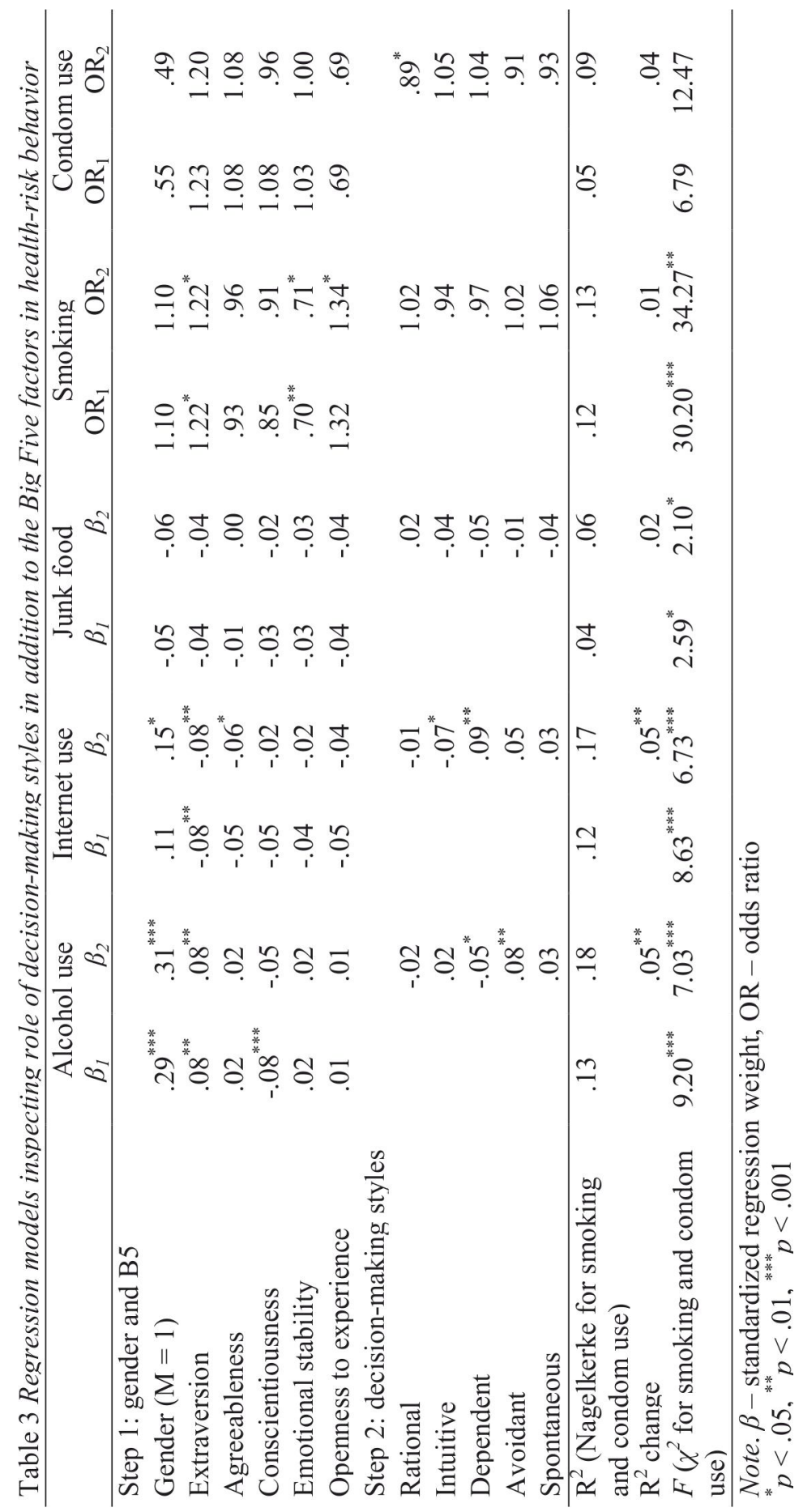


than from oneself(Wood \& Highhouse, 2014). Similar results were found when decision-making styles, cognitive styles and the Big Five factors were used to explain general decision outcomes as an overall indicator of decision quality including a variety of real life situations (Dewberry, Juanchich, \& Narendran, 2013). While four out of the eight inspected decisionmaking styles were significant predictors of decision outcomes, only the vigilant style (style from The Melbourne Decision Making Questionnaire which is similar to the rational style in the GDMS) remained significant after adding the cognitive styles and personality factors. When summarized together with the current results and other studies (e.g., Bruine de Bruin, Parker, \& Fischhoff, 2007), the decision-making styles seem to be related to various decision outcomes although it is likely that other variables, predominantly personality factors and the subjective evaluation of one's own styles and decision outcomes, can partially explain these relationships.

Although decision-making styles offer just a little in addition to personality factors when explaining risk behavior, some of them were found to be significant predictors of certain types of risk behavior. The most dominant is the position of the dependent style whose higher score positively predicted problematic internet use and negatively alcohol use. This points to the impossibility of generalizing its role across types of health-risk behavior. While people who rely more on others while making decisions tend to use the internet excessively, they also have lower alcohol related problems. This finding is in line with previous studies, which have reported negative association of perceived social support (positive correlate of the avoidant style, Bavolar \& BacikovaSleskova, 2018) with alcohol use (e.g., Steptoe et al., 1996). On the other hand, the internet may serve as another source of support and, according to the positive association between the avoidant style and internet use, a way to postpone making decisions.

The avoidant decision-making style was found to be a significant predictor of problematic internet use and alcohol use (in this case only without the Big Five factors as predictors). This style is similar to the group of avoidant coping styles that are negatively related to health protective factors (Nes \& Segerstrom, 2006; Sagone \& DeCaroli, 2014) and positively to psychological distress (Miller etal., 1996). More specifically, the avoidant coping is related to higher alcohol use (Hasking, Lyvers, \& Carlopio, 2011) and drug use (Nyamathi, Stein, \& Brecht, 1995). Thus, the use of this style can be regarded as a risk factor in multipledomains, although it was confirmed only in some cases in this study. It can point to some differences between internet use and other investigated kinds of risk behavior - possibly the easiest way to avoid other responsibilities (including making decisions), in comparison with other risk behavior types, is to use internet services such as social networks that are available immediately.

While the rational (analytical) and intuitive (experiential) styles are considered to be the main modes of information processing (Evans, 2008) and the rational decision-making style helps one to have better general decision outcomes (Bruine de Bruin, Parker, \& Fischhoff, 2007; Juanchich et al., 2016), their role in risk behavior seems inferior. While only the intuitive style was associated with some kind of risk behavior (internet use), the role of the rational style in condom use and intuitive style in junk food consumption was also identified in the differences between the regression models including and not including the Big Five factors. The rational style helps one to use protection during the first sexual intercourse, which can be considered an example of highly rational consideration of potential outcomes emphasized in all safe-sex recommendations. The question is why it is not manifested in other risk 
behavior types as warnings about the consequences of excessive alcohol drinking, cigarette smoking or unhealthy eating habits are often publicly emphasized.

One of the limitations of the present research is the method of data collection. As most participants completed the measures via the internet and only self-reported data were available, the discrepancy between the reported and real behavior is possible. Some kinds of risk behavior are difficult to recall (e.g., frequency of alcohol use during a time period) or in some cases social desirability can play an important role (Brener, Billy, \& Grady, 2003). Moreover, some risk behaviors are very sensitive to report or subjects can purposely underestimate or overestimate the frequency of their occurrence according to the perceived expectations. The used measures asked about the frequent behavior in past decision-making situations, but people's perceptions can be confused and their ability to recall is questionable.

Another problem can arise from the substantial drop-off between the first and second round of data collection in part of the sample, but a great concordance of the found correlations between decision-making styles and the Big Five factors with previous studies (Dewberry, Juanchich, \& Narendran, 2013; Wood \& Highhouse, 2014) and only slight differences in risk behavior and personality factors between participants from the first and the second round indicate that the decrement rate between the two rounds have not influenced the present findings markedly. Another problem is visible in the Big Five measurement, when the used questionnaire (TIPI) with only two items for each factor had lower internal consistency coefficients. This is common in few-items scales (Schmitt, 1996). A more reliable measure of personality factors should be used to verify the present results.

To conclude, the study gives an insight into the role of decision-making styles in different types of risk behavior and complements past studies dealing with general decision outcomes. The current results can be a starting point for more specific research plans taking into consideration the interaction of decision-making styles with other factors including other personality and socio-psychological characteristics. From the practical view, possible implications may include prevention and intervention programs for groups with a higher risk of the studied decision outcomes where enhancing a certain approach to making decisions can prevent some kinds of risk behavior. As the dependent and avoidant styles were the strongest predictors of risk behavior, the major message is to encourage a more serious decision making approach including considering the potential of short-term as well as long-term consequences of risk behavior without avoiding making decisions.

\section{References}

Anderson, E. L., Steen, E., \& Stavropoulos, V. (2017) Internet use and problematic Internet use: A systematic review of longitudinal research trends in adolescence and emergent adulthood. International Journal of Adolescence and Youth, 22(4), 430-454.

Al-Gamal, E., Alzayyat, A., \& Ahmad, M. M. (2016). Prevalence of Internet addiction and its association with psychological distress and coping strategies among university students in Jordan. Perspectives in Psychiatric Care, 52(1), 49-61.

Appelt, K. C., Milch, K. F., Handgraaf, M. J., \& Weber, E. U. (2011). The Decision Making Individual Differences Inventory and guidelines for the study of individual differences in judgment and decision-making research. Judgment and Decision Making, 6(3), 252-262.

Bavolar, J., \& Bacikova-Sleskova, M. (2018). Psychological protective factors mediate the relationship between decision-making styles and mental health. Current Psychology, 1-10.

Bavol'ár, J., \& Orosová, O. (2015). Decision-making styles and their associations with decision-making competencies and mental health. Judgment and Decision Making, 10(1), 115-122.

Bohn, M. J., Babor, T. F., \& Kranzler, H. R. (1995). The Alcohol Use Disorders Identification Test (AUDIT): 
Validation of a screening instrument for use in medical settings. Journal of Studies on Alcohol, 56(4), 423432.

Brener, N. D., Billy, J. O., \& Grady, W. R. (2003). Assessment of factors affecting the validity of selfreported health-risk behavior among adolescents: Evidence from the scientific literature. Journal of Adolescent Health, 33(6), 436-457.

Bruine de Bruin, W., Parker, A. M., \& Fischhoff, B. (2007). Individual differences in adult decision-making competence. Journal of Personality and Social Psychology, 92(5), 938-956.

Caplan, S. E. (2010). Theory and measurement of generalized problematic Internet use: A two-step approach. Computers in Human Behavior, 26(5), 1089-1097.

Çavuşoğlu, F., \& Bahar, Z. (2010). Influence of socioeconomic factors and family social support on smoking and alcohol use among health school students. International Journal of Caring Sciences, 3(2), $77-$ 84.

Clark, L., Robbins, T. W., Ersche, K. D., \& Sahakian, B. J. (2006). Reflection impulsivity in current and former substance users. Biological Psychiatry, 60(5), 515-522.

Coëffec, A. (2011). Les apports du modèle des cinq grands facteurs dans le domaine de l'alcoolodépendance [Big five factor contributions to addiction to alcohol]. L'Encéphale, 37(1), 7582

Cooper, M. L., Russell, M., Skinner, J. B., Frone, M. R., \& Mudar, P. (1992). Stress and alcohol use: Moderating effects of gender, coping, and alcohol expectancies. Journal of Abnormal Psychology, 101(1), 139-152.

Costa, P. T., \& MacCrae, R. R. (1992). Revised NEO Personality Inventory (NEO PI-R) and NEO FiveFactor Inventory (NEO FFI): Professional manual. Psychological Assessment Resources.

Deshpande, S., Basil, M. D., \& Basil, D. Z. (2009). Factors influencing healthy eating habits among college students: An application of the health belief model. Health Marketing Quarterly, 26(2), 145164.

Dewberry, C., Juanchich, M., \& Narendran, S. (2013). Decision-making competence in everyday life: The roles of general cognitive styles, decision-making styles and personality. Personality and Individual Differences, 55(7), 783-788.

Donohew, L., Zimmerman, R., Cupp, P. S., Novak, S., Colon, S., \& Abell, R. (2000). Sensation seeking, impulsive decision-making, and risky sex: Implications for risk-taking and design of interventions. Personality and Individual Differences, 28(6), 10791091.
Feil, J., \& Hasking, P. (2008). The relationship between personality, coping strategies and alcohol use. Addiction Research \& Theory, 16(5), 526-537.

Friedman, H. S. (2000). Long-term relations of personality and health: Dynamisms, mechanisms, tropisms. Journal of Personality, 68(6), 1089-1107.

Galotti, K. M., Ciner, E., Altenbaumer, H. E., Geerts, H. J., Rupp, A., \& Woulfe, J. (2006). Decision-making styles in a real-life decision: Choosing a college major. Personality and Individual Differences, 41(4), 629-639.

Gorodetzky, H., Sahakian, B. J., Robbins, T. W., \& Ersche, K. D. (2011). Differences in self-reported decision-making styles in stimulant-dependent and opiate-dependent individuals. Psychiatry Research, 186(2), 437-440.

Gosling, S. D., Rentfrow, P. J., \& Swann, W. B. (2003). A very brief measure of the Big-Five personality domains. Journal of Research in Personality, 37(6), 504-528.

Hasking, P., Lyvers, M., \& Carlopio, C. (2011). The relationship between coping strategies, alcohol expectancies, drinking motives and drinking behaviour. Addictive Behaviors, 36(5), 479-487.

Hong, R. Y., \& Paunonen, S. V. (2009). Personality traits and health-risk behaviours in university students. European Journal of Personality, 23(8), 675-696.

Jones, R. M., Ross, C. N., \& Hartmann, B. R. (1992). An investigation of cognitive style and alcohol/ work-related problems among naval personnel. Journal of Drug Education, 22(3), 241-251.

Juanchich, M., Dewberry, C., Sirota, M., \& Narendran, S. (2016). Cognitive reflection predicts real-life decision outcomes, but not over and above personality and decision-making styles. Journal of Behavioral Decision Making, 29(1), 52-59.

Keller, S., Maddock, J. E., Hannöver, W., Thyrian, J. R., \& Basler, H. D. (2008). Multiple health risk behaviors in German first year university students. Preventive Medicine, 46(3), 189-195.

Kozhevnikov, M. (2007). Cognitive styles in the context of modern psychology: Toward an integrated framework of cognitive style. Psychological Bulletin, 133(3), 464-481.

Martin, J. L., Groth, G., Longo, L., Rocha, T. L., \& Martens, M. P. (2015). Disordered eating and alcohol use among college women: Associations with race and big five traits. Eating Behaviors, 17, 149152 .

McCann, S. J. (2010). Subjective well-being, personality, demographic variables, and American state differences in smoking prevalence. Nicotine \& Tobacco Research, 12(9), 895-904.

Meader, N., King, K., Moe-Byrne, T., Wright, K., Graham, H., Petticrew, M., Power, C., White, M., \& 
Sowden, A. J. (2016). A systematic review on the clustering and co-occurrence of multiple risk behaviours. BMC Public Health, 16(1), 657.

Miller, D. L., Manne, S. L., Taylor, K., Keates, J., \& Dougherty, J. (1996). Psychological distress and wellbeing in advanced cancer: The effects of optimism and coping. Journal of Clinical Psychology in Medical Settings, 3(2), 115-130.

Nes, L. S., \& Segerstrom, S. C. (2006). Dispositional optimism and coping: A meta-analytic review. Personality and Social Psychology Review, 10(3), 235-251.

Nyamathi, A., Stein, J. A., \& Brecht, M. L. (1995). Psychosocial predictors of AIDS risk behavior and drug use behavior in homeless and drug addicted women of color. Health Psychology, 14(3), 265-273.

Parker, A. M., De Bruin, W. B., \& Fischhoff, B. (2007). Maximizers versus satisficers: Decision-making styles, competence, and outcomes. Judgment and Decision Making, 2(6), 342-350.

Pitel, L., \& Mentel, A. (2017). Decision-making styles and subjective performance evaluation of decisionmaking quality among hospital nurses. Studia Psychologica, 59(3), 217-231.

Phillips, J. G., \& Ogeil, R. P. (2011). Decisional styles and risk of problem drinking or gambling. Personality and Individual Differences, 51(4), 521-526.

Racette, S. B., Deusinger, S. S., Strube, M. J., Highstein, G. R., \& Deusinger, R. H. (2005). Weight changes, exercise, and dietary patterns during freshman and sophomore years of college. Journal of American College Health, 53(6), 245-251.

Renau, V., Oberst, U., Gosling, S., Rusińol, J., \& Chamarro, A. (2013). Translation and validation of the ten-item-personality inventory into Spanish and Catalan. Aloma: Revista de Psicologia, Ciències de l'Educació $i$ de l'Esport, 31(2), 85-92.

Sacco, P., Bucholz, K. K., \& Harrington, D. (2014). Gender differences in stressful life events, social support, perceived stress, and alcohol use among older adults: Results from a national survey. Substance Use \& Misuse, 49(4), 456-465.

Sagone, E., \& De Caroli, M. E. (2014). A correlational study on dispositional resilience, psychological well- being, and coping strategies in university students. American Journal of Educational Research, 2(7), 463-471.

Scott, S. G., \& Bruce, R. A. (1995). Decision-making style: The development and assessment of a new measure. Educational and Psychological Measurement, 55(5), 818-831.

Schmitt, N. (1996). Uses and abuses of coefficient alpha. Psychological assessment, 8(4), 350-353.

Steptoe, A., Wardle, J., Cui, W., Bellisle, F., Zotti, A. M., Baranyai, R., \& Sanderman, R. (2002). Trends in smoking, diet, physical exercise, and attitudes toward health in European university students from 13 countries, 1990-2000. Preventive medicine, 35(2), 97-104.

Steptoe, A., Wardle, J., Pollard, T. M., Canaan, L., \& Davies, G. J. (1996). Stress, social support and healthrelated behavior: A study of smoking, alcohol consumption and physical exercise. Journal of Psychosomatic Research, 41(2), 171-180.

Tuinstra, J. (1998). Health in adolescence: An empirical study of social inequality in health, health risk behaviour and decision making styles. (Doctoral dissertation, University of Groningen). Retrieved August 18, 2015, from http://www.rug.nl/research/portal/files/10658842/c8.pdf.

Westmaas, J. L., Bontemps-Jones, J., \& Bauer, J. E. (2010). Social support in smoking cessation: Reconciling theory and evidence. Nicotine \& Tobacco Research, 12(7), 695-707.

Wood, N. L., \& Highhouse, S. (2014). Do self-reported decision styles relate with others' impressions of decision quality? Personality and Individual Differences, 70, 224-228.

Zorlu, N., Gelal, F., Kuserli, A., Cenik, E., Durmaz, E., Saricicek, A., \& Gulseren, S. (2013). Abnormal white matter integrity and decision-making deficits in alcohol dependence. Psychiatry Research: Neuroimaging, 214(3), 382-388.

Zvolensky, M. J., Taha, F., Bono, A., \& Goodwin, R. D. (2015). Big five personality factors and cigarette smoking: A 10-year study among US adults. Journal of Psychiatric Research, 63, 91-96. 